\title{
A CONSTRUÇÃO DO MUNDO: O PAPEL DA ARTE NO INTER HOMINES ESSE
}

\section{Guilherme Mautone ${ }^{1}$}

\begin{abstract}
RESUMO
O artigo procura explorar o papel da arte na construção da noção de mundo. Ela aparece no pensamento de Hannah Arendt sob a égide de uma herança conceitual que remonta a Heidegger e Husserl e abarca a pletora de coisas eminentemente humanas, em contraste com aquelas que são naturalmente dadas. Por outro lado, exploramos a filosofia tardia de Wittgenstein através da noção de forma de vida que, em nossa visão, consiste em um operador estrutural para a compreensão da linguagem, da arte e da cultura. Nossa conjectura é de que os empreendimentos de Arendt e de Wittgenstein resguardam certos pontos de convergência.
\end{abstract}

Palavras-chave: Arte. Mundo. Formas de Vida. Arendt. Wittgenstein.

\begin{abstract}
This paper aims to explore the role of art on the construction of the notion of world, which appears at Hannah Arendt's thought under Heidegger's and Husserl's conceptual heritage, and covers the plethora of things that are intrinsically human, by contrast to those naturally given. By the other side, we explore Wittgenstein's late philosophy through the notion of forms of life, which, in our perspective, consists in a structural operator to the comprehension of language, art and cultures. Our conjecture is that Arendt and Wittgenstein's philosophical enterprises share a few common features.
\end{abstract}

Keywords: Art. World. Forms of Life. Arendt. Wittgenstein.

\footnotetext{
${ }^{1}$ Bacharel, Mestre e doutorando (do $4^{\mathrm{a}}$ ano) em Filosofia pela UFRGS com pesquisa em Filosofia da Arte e Estética. É docente da Casamundi Cultura e Editor da Revista PHILIA | Filosofia, Literatura \& Arte. A pesquisa é financiada pela CAPES e orientada pela Prof ${ }^{\mathrm{a}}$. $\mathrm{Dr}^{\mathrm{a}}$. Kathrin Holzermayr Rosenfield. E-mail: guimautone@gmail.com.
} 


\section{Preâmbulo}

Ao longo deste texto tentarei explorar o papel da arte na construção do mundo. A ideia que alicerça um enunciado como esse ('construção do mundo') é a de que o mundo não é, retomando as formulações categoriais de Aristóteles (2003, Dzeta, 7, 1032 12, p. 10), nem por natureza (physei), nem por acaso ou espontaneamente (to taumathou), mas por arte (technè). Ou seja, sua origem ontológica - sua causa material - não é, por um lado, um produto da natureza ou a natureza ela mesma; e não é, por outro lado, um produto do acaso, da arbitrariedade. Diferentemente disto, o 'mundo' figurará no empreendimento arendtiano, por exemplo, enquanto um resultado da produção humana, um resultado daquilo que Arendt chamará de obra e que configura e determina a seara específica do homo faber, fabricante, fabricador, fazedor das coisas.

Para tanto, numa seção inicial, partiremos de algumas análises das concepções arendtianas encontradas n' A Condição Humana, em especial seu desenvolvimento do conceito de obra e sua reflexão sobre a obra de arte. Numa segunda seção, comentaremos o empreendimento wittgensteiniano encontrado em Investigações Filosóficas, em especial a noção de formas de vida (Lebensform) que é ali introduzida. E, como encerramento, procuraremos cruzar os dois empreendimentos, mostrando suas interseções ou afastamentos. $\mathrm{O}$ interesse mais geral desse texto, e que lhe serve em certo sentido como pano de fundo, é o impacto dessas reflexões - tanto a arendtiana, como a wittgensteiniana - no estudo filosófico da arte. Portanto, em diversos momentos o texto buscará reportar-se, através de exemplos ou de problemas, àquilo que se convencionou em chamar, especialmente depois de Arthur Danto (1969, p. 571-584), de mundo da arte.

\section{Os conceitos de mundo, obra e arte em Hannah Arendt}

Parece-me relevante que a consideração de qualquer conceito, em qualquer pensador, não seja feita de maneira simplista. Se pensarmos nas abordagens analíticas e, em especial, na filosofia da linguagem ordinária que nasce, em certo sentido, com Wittgenstein, seremos obrigados a considerar que termos, noções e conceitos são transmitidos diacronicamente pelos 
usuários da linguagem - e isso remete para a imagem de uma cadeia histórica de transmissão de termos e de deferência de seus sentidos. ${ }^{2}$ Desse modo, amputar da análise essa consideração histórica, relativa à herança conceitual e ao legado filosófico, acaba por tornar o estudo um tanto deficitário. Assim, parece-me salutar realizar esse tipo de empreendimento também com as análises das noções de mundo e de obra em Arendt. Assim, procuraremos pelo menos indicar onde essa transmissão pode ser sentida com maior acento.

\subsection{Mundo}

À primeira vista, Hannah Arendt herda a noção de mundo dos empreendimentos fenomenológicos de Husserl e de Heidegger. Conforme aponta Passos (2013, p. 78), em Heidegger, no célebre texto A origem da obra de arte, já se percebe uma compreensão da obra de arte enquanto uma espécie de conciliador, ou melhor, articulador entre duas instâncias - de um lado a Terra e, de outro lado, o mundo. Nesta perspectiva, Heidegger estaria compreendendo a dimensão da Terra como tudo aquilo que se encontra disponível naturalmente para o homem, como aquilo que já está dado, ainda que o homem não estivesse. Diferentemente disto, sua compreensão da dimensão do mundo diz respeito ao âmbito específico de construção humana, de fabricação de sentido, de criação de um contexto ou de inúmeros, um locus no qual “o Dasein realmente vive, encontra-se, está lançado" (Ibidem, p. 79). Assim, lançando mão de uma analogia que, no contexto de A origem da obra de arte é, no mínimo, coerente, poderíamos pensar nestes termos, por exemplo, uma escultura em cerâmica. Nela, em um sentido heideggeriano, encontraríamos presentes as duas instâncias - Terra e mundo - conciliadas. O barro, componente primordial da fabricação da cerâmica, encontrado naturalmente pelo homem em um estado bruto e não-mediado pela intenção, presentificaria o elemento Terra; por outro lado, esse barro, depois de recolhido de seu lugar habitual, preparado, trabalhado e modelado por uma sequência intencional tipicamente humana, capaz de nele corporificar sentidos e representações, presentificaria então o elemento mundo. Assim, a obra de

\footnotetext{
${ }^{2}$ Cf. Peter Geach, Logic Matters (The Perils of Pauline), 1972. E Cf. Saul Kripke, Naming and Necessity, 1972.
} 
arte, o produto final de todo um processo de fabricação que conjuga um elemento terrestre (ou telúrico) a elementos mundanos, seria capaz de evidenciar, fazer-ver, expor a articulação entre essas duas instâncias, Terra e mundo.

Heidegger parece, por sua vez, herdar de Husserl essa distinção, essa diferenciação categorial, presente nos termos Terra e mundo. Ainda de acordo com Passos (2013), a distinção entre estes termos em Husserl evidencia uma enorme relevância no panorama conceitual de sua filosofia, uma vez que nela a Terra será entendida como o solo no qual uma pluralidade de mundos poderá ser reificada - diferentes povos, governos, culturas, instituições, etc. (Ibidem, p. 79). Nesse sentido, torna-se, como em Heidegger, bastante claro o escopo semântico que se quer dar a esses dois termos, uma vez que Terra aparece sempre como o âmbito natural, dado desde sempre, independente da vida humana e separado dela, enquanto que mundo aparece enquanto o emaranhado complexo de práticas que sustentam e garantem a fixidez da vida humana na Terra. É interessante perceber como Passos (2013) desenvolve sua análise, primeiro de Heidegger, depois de Husserl, no que diz respeito a este par de noções; e também como procura, respeitando as nuances teóricas e conceituais de cada pensador, mostrar que o substrato conceitual de Terra remete à naturalidade, enquanto que o substrato conceitual de mundo à artificialidade. A Terra é natural e autônoma em relação ao homem, sua fabricação e seu engenho; enquanto mundo não é, mas depende dele e só ganha sentido quando pensado e visto a partir de sua inserção e atividade.

É nesse sentido que podemos dizer que Husserl realiza um movimento de "voltar às próprias coisas", no intuito de compreender que o mundo da vida (Lebenswelt) constitui-se como âmbito sobre o qual acontecem as vivências humanas, que aparecem como um constante pano de fundo, ao qual toda análise tem às suas costas sem poder negá-lo ou desvencilhar-se dele quando se pretende realizar um exame técnico, um experimento científico, ou uma compreensão de cunho político. Atrás dessas visadas percebe-se que pulula um mundo artificial, criado pelas mãos humanas, que deve ser preservado para que possamos falar da existência de homens em seu sentido autêntico (Ibidem, p. 90).

Embora essa breve genealogia do mundo entre Husserl, Heidegger e Arendt feita por nós tenha objetivado, primeiramente, apontar um certo encadeamento de heranças e legados conceituais e filosóficos entre estes três pensadores, é bastante importante mencionar que tal herança não se dá na 
ausência de mediação ou através de uma assunção dogmática, sem questionamentos ou dimensionamentos filosóficos. É que, para Arendt, pelo menos assim nos parece, o conceito de mundo será sim pensado a partir desse horizonte heideggeriano mas será igualmente dimensionado e matizado pelos seus próprios interesses. Assim, o conceito de mundo em Hannah Arendt aparecerá vinculado de forma essencial ao seu desenvolvimento teórico da pluralidade na política, coisa que Heidegger não fez. É nesse sentido que o pensamento arendtiano nos parece reelaborar a tradição filosófica na qual inseriu-se, confrontando-o às novas experiências sociológicas, políticas e históricas do século XX. Se em Husserl e em Heidegger a distinção Terra/ mundo ocupava um lugar de centralidade numa espécie de consideração ontológica, de ocupação metafísica, então agora, com Arendt, a centralidade dessa investigação sofrerá um deslocamento e será aproximada de investigações de outra ordem, capazes de confrontar a filosofia e a política:

É da própria natureza da filosofia lidar com o homem no singular, ao passo que a política não poderia sequer ser concebida se os homens não existissem no plural. Para dizer de outro modo: as experiências do filósofo como filósofo são experiências com a solidão que, para o homem como ser político, ainda que essenciais, não deixam de ser marginais. Pode ser que (...) o conceito heideggeriano de "mundo" seja um passo para sair desta dificuldade (Arendt, 2002, p. 87).

Ora, nesse sentido a reelaboração arendtiana se tornar bastante relevante, uma vez que a pensadora alemã não está mais interessada na centralidade de uma investigação estritamente metafísica sobre o homem no singular. Embora reconheça-a como essencial e relevante, da perspectiva do pensamento político ela é apenas e sempre marginal para Arendt, uma vez que o homem em sua pluralidade é que deve ocupar o lugar de centralidade aí. E falar do homem em sua pluralidade será, para Arendt, falar do homem como construtor do mundo, de mundos diferentes, diversos, plurais.

Arendt passa a reconhecer a importância da concepção heideggeriana de "mundo" e do Dasein como "ser-no-mundo", para a sua própria articulação conceitual da "pluralidade" como a condição básica da vida política. Daí a sua sugestão, na conferência de 1954, intitulada Interesse pela política no recente pensamento filosófico europeu, de que "é exatamente porque define a existência humana como ser-no-mundo que Heidegger insiste em dotar de significado filosófico as estruturas da vida cotidiana. Estas são completamente incompreensíveis se o homem não for entendido, antes de tudo, como ser que existe junto com outros homens". É também 
a partir dessa nova perspectiva interpretativa, que confere uma dimensão política inovadora aos conceitos filosóficos de Ser e Tempo, que Arendt passa a reconhecer o caráter "penetrante" das "descrições fenomenológicas" dos parágrafos 26 e 27, concordando com certos aspectos da crítica heideggeriana ao "falatório" (Gerede) que inunda o cotidiano das sociedades de massa e oculta as possibilidades mais originárias do ser-com (Duarte, 2003, p. 327).

Dessa maneira, parece-nos bastante claro como e também porque Arendt confere um matiz político às considerações inicialmente ontológicas de Heidegger (e de Husserl) sobre os conceitos de Terra e de mundo, dimensionando assim a sua própria herança e tradição filosófica. Falar, assim, da vivência do homem com outros homens - que é recuperar o aspecto da pluralidade - exige que se considere sumariamente a existência prévia de um terreno comum, de um topós compartilhado e dividido no qual essa vivência se poderá sustentar. Esse topós nos parece ser o mundo (de Heidegger e de Husserl, revisitado por Arendt).

\subsection{Obra}

Considerar, portanto, o mundo enquanto o lugar, o topós, específico da criação humana e especialmente no panorama arendtiano do inter homines esse, ou seja, o lugar privilegiado do aparecimento dessa vivência política, levará - parece-nos - Arendt a aprimorar conceitualmente as especificidades desse lugar. O mundo, assim compreendido, é o lugar do trabalho, da obra e da ação. Mas é através da obra, distinta do trabalho, que o mundo ganha sua permanência e sua efetividade.

A obra de nossas mãos, distintamente do trabalho do nosso corpo - o homo faber, que produz e literalmente "opera em", diferentemente do animal laborans, que trabalha e "se mistura com" -, fabrica a infinita variedade de coisas cuja soma total constitui o artifício humano (Arendt, 2013, p. 169).

Dessa maneira, é a obra das mãos que fabrica e constrói todas as diferentes coisas que, juntas, expressam plenamente a noção desse artificio humano. Arendt (2013, p. 169) vai mais além ao desdobrar essas ideias, uma vez que nos indica que é esse artificio que garantem os aspectos de solidez, de estabilidade, sem os quais o homem não poderia sequer sobreviver em função de sua mortalidade e sua instabilidade natural. Esse ponto, pelo menos assim nos parece, procura explorar conceitualmente com cada vez mais 
arrojo a ideia, já mencionada por nós, de que o opera enquanto parâmetro de distinção entre Terra e mundo são os aspectos da naturalidade e da artificialidade, respectivamente. A obra, no entanto, ganha, diferentemente do trabaIho, um caráter de coisa, de objetividade, de produto de reificação específica em Arendt. Ela estabiliza a vivência dos homens e suportam as demandas e as carências de seus construtores e fabricantes.

\begin{abstract}
É essa durabilidade que confere às coisas do mundo sua relativa independência dos homens que as produziram e as utilizam, sua "objetividade", que as faz resistir, "se opor" [stand for] e suportar, pelo menos durante algum tempo, as vorazes necessidades e carência de seus fabricantes e usuários vivos. Desse ponto de vista, as coisas do mundo têm a função de estabilizar a vida humana; sua objetividade reside no fato de que - contrariando Heráclito, que disse que o mesmo homem jamais pode entrar no mesmo rio - os homens, a despeito de sua natureza sempre cambiante, podem recobrar sua constância [sameness], isto é, sua identidade, por se relacionarem com a mesma cadeira e a mesma mesa. Em outras palavras, contra a subjetividade dos homens afirma-se a objetividade do mundo feito pelo homem, e não a sublime indiferença de uma natureza intacta, cuja esmagadora força elementar os forçaria, ao contrário, a voltear inexoravelmente no círculo do seu próprio movimento biológico, que se harmoniza estreitamente com o movimento cíclico global do reino da natureza (Ibidem, p. 170-171).
\end{abstract}

Dessa maneira, identificar a obra enquanto aquilo que aparece e que garante, ao homem, certa estabilidade frente a sua natureza cambiável e mutante, significa também identificar o terreno comum no qual o homem, mais do que sua humanidade, tem garantida a sua possibilidade de discurso e de ação, ou seja, tem garantida a sua possibilidade de realização da política. Nesse sentido, é interessante pensar - mais à título de curiosidade biográfica - na participação de Hannah Arendt, depois do fim da Segunda Guerra Mundial, em seu retorno à Alemanha, em uma organização cujo objetivo principal era recuperar as heranças culturais judaicas que haviam sido sumariamente condenadas pelos nazistas. ${ }^{3}$ É bastante provável que, por trás dessa adesão e dessa participação, Arendt tivesse certa clareza para si mesma de que a recuperação dessas coisas, cuja natureza transcende a imediatez e pouca durabilidade daquilo que constitui o âmbito do trabalho, era também a recuperação de algo relativo ao âmbito da obra. Logo, recuperar o que é referente à obra permite, em alguma instância, recuperar também o lastro de

\footnotetext{
${ }^{3}$ Cf. Entrevista a Zur Person, 1964. Disponível em: www. youtube.com/watch? $\mathrm{v}=\mathrm{dsoImQfVsO}$. Acesso em: 27.04.2020
} 
objetividade, mundanidade e estabilidade, o "lar confiável" (Arendt, 2013, p. 209) que viabiliza o inter homines esse, o discurso, a ação e a política.

\subsection{Arte}

Trabalhados, portanto, o conceito de obra enquanto aquilo que garante aos homens a estabilidade de sua vivência e ação, e o conceito de mundo como o terreno que permite ao homem o enfrentamento saudável da pluralidade essencial do mundo, é possível dentro do empreendimento arendtiano encontrar também um lugar específico no qual apresentar a obra de arte. Esse lugar será, parece-nos, no próprio bojo da obra.

Entre as coisas que conferem ao artifício humano a estabilidade sem a qual ele jamais poderia ser um lar confiável para os homens há uma quantidade de objetos estritamente sem utilidade alguma e que, ademais, por serem únicos, não são intercambiáveis e, portanto, resistem à igualação por meio de um denominador comum como o dinheiro; se ingressam no mercado de trocas, só podem ser apreçados arbitrariamente. Além disso, o relacionamento adequado com uma obra de arte certamente não é 'usá-la'; pelo contrário, ela tem de ser cuidadosamente resguardada de todo o contexto dos objetos de uso comuns para que possa alcançar o seu lugar adequado no mundo (Ibidem, p. 209).

Mais uma vez, a ideia de 'vivência' é aqui suplementada pela de 'lar confiável', de lugar no qual se dá a possibilidade do inter homines esse. Embora esse lugar de confiança seja garantido por mesas e cadeiras e pela pletora de utilidade desses objetos que - diferentemente daqueles que são resultado do trabalho - não sofrem um processo quase instantâneo de desaparecimento pela voracidade do consumo humano, mas se submetem a um processo distinto, o de um longo e espraiado desgaste temporal que poderíamos qualificar de cotio; mesas e cadeiras não compõem o escopo total da obra em Hannah Arendt. As obras de arte, que são coisas objetivas, são artefatos $^{4}$, engastam-se junto das mesas e das cadeiras na composição desse mo-

\footnotetext{
${ }^{4}$ Não é sem sentido afirmar que, dentro das concepções arendtianas e dentro do tempo no qual irromperam, não caracteriza um erro grosseiro afirmar que as obras de arte são, de fato, artefatos. É bem provável que Arendt estivesse, por residir nos Estados Unidos, familiarizada com a arte moderna e, em especial, com todo o modernismo americano cujo expoente foi, desde Clement Greenberg, a action painting e os drippings de Jackson Pollock. No entanto é importante mencionar que, já em 1958, ano em que $A$ condição humana é publicada, já existissem dentro do mundo da arte uma série de experimentações artisticamente relevantes (por exemplo, o Conceitualismo ou Arte Conceitual) que prouraram subverter, inclusive, a insistência do que chamamos de suporte tradicional. À título de curiosidade,
} 
biliário metafísico do mundo. As distinções entre, de um lado, uma mesa e o Extase de Santa Teresa D'Ávila de Bernini e, de outro lado, uma cadeira e Guernica de Picasso, correspondem aos modos de uso desses objetos. Usase uma mesa, uma cadeira, de uma forma bastante diferente da qual se 'usa' a escultura de Bernini e a pintura de Picasso. Nesse ponto, Arendt é excepcionalmente clara ao dizer que, frente à obra de arte, não cabe um 'uso' possível, pois a arte precisa ser resguardada desse contexto de uso dos outros objetos que compreendem a obra. Ela comenta, ainda que o faça en passant, sobre um "lugar adequado" (Arendt, 2013, p. 209) que as obras tem no mundo sem, no entanto, explicitar qual seria esse lugar ou qual seria sua função.

Hannah Arendt procura em seguida dimensionar ainda mais a discussão sobre o não-uso da obra de arte. Ela afirmará que a arte é um objeto mais intensamente mundano que os demais objetos e que ela parece não sofrer - precisamente por não ser 'usada' - do desgaste, do cotio, que sofrem os objetos que são diuturnamente usados e que compõem também o mundo (mesas, cadeiras, etc.). Isso indica que Arendt está em vias de pensar uma durabilidade ainda maior, e talvez ainda mais intensamente vinculada ao sentido de obra, para as coisas artísticas.

Dada a sua excepcional permanência, as obras de arte são as mais intensamente mundanas de todas as coisas tangíveis; sua durabilidade permanece quase inalcançada pelo efeito corrosivo dos processos naturais, uma vez que não estão sujeitas ao uso por criaturas vivas, um uso que, na verdade, longe de realizar sua finalidade inerente - como a finalidade de uma cadeira é realizada quando alguém nela se senta - só pode destruí-la. Assim a durabilidade das obras de arte é de uma ordem superior àquela de que todas as coisas precisam para existir (Ibidem, p. 209).

É, portanto, precisamente na discussão sobre a durabilidade e a permanência distintivas das obras de arte que Arendt consegue engatar, pelo menos em nossa perspectiva, a noção de mundo da forma mais relevante. A permanência secular, por vezes milenar, da obra de arte, sua persistência, sua presença continuada em diferentes gerações e culturas, é que revela, desdobra, evidencia o caráter de mundo-coisa (thing-world) enquanto a casa não mortal - porque durável, permanente - para seres mortais. Assim o ho- 
mem, mortal, limitado pelo seu ciclo vital e pela sua limitação biológica, depara-se, diante da arte, com a imortalidade e com a permanência do seu mundo. A arte, parece, garante-o como sua condição de possibilidade.

Nessa permanência, a estabilidade do artificio humano, que jamais pode ser absoluta por ele ser habitado e usado por mortais, adquire representação própria. Em nenhuma outra parte a mera durabilidade do mundo feito pelo homem aparece com tal pureza e claridade; em nenhuma outra parte, portanto, esse mundo-coisa [thing-world] se revela tão espetacularmente como a morada não mortal para seres mortais. É como se a estabilidade mundana se tornasse transparente na permanência da arte, de sorte que certo pressentimento de imortalidade (...) tornou-se tangivelmente presente para fulgurar e ser visto, soar e ser escutado, falar e ser lido (Ibidem, $\mathrm{p}$. 210).

É curioso como Arendt inverte a ordem da investigação ao falar de arte. Em vez de considerar o que seria mais natural na ordem da razão, ou seja, considerar a essência da arte, seus aspectos metafísicos e ontológicos para, depois, falar de sua recepção ou sua experimentação pelos sujeitos; Arendt tecerá, primeiro, considerações estéticas, relativas ao engajamento da sensibilidade humana com certos objetos específicos, entre eles as obras de arte, para, depois, comentar sobre possíveis aspectos essenciais que nos apontariam no caminho de uma busca metafísica pela essência dessas coisas. Depois de considerar essa experiência estética intricada do homem diante da arte - experiência pautada pela mirada na imortalidade e na durabilidade do mundo - é que Arendt fará comentários que poderíamos entender enquanto essenciais. Quando diz que a "fonte imediata da obra de arte é a capacidade humana de pensar" (Ibidem, p. 210), Arendt nos coloca nesse caminho, embora um tanto ambiguamente. A capacidade humana de pensar, no entanto, não opera sozinha no terreno da arte, mas "relaciona-se com o sentimento e transforma seu desalento mudo e inarticulado" (Ibidem, p. 210). Com isso, Arendt parece também pretender chamar atenção ao aspecto expressivo da arte, sugerindo que o artista, fazendo uso do seu pensar aliado aos seus sentimentos é capaz de, através da construção artística (que é, pensando nos suportes tradicionais, algo da ordem da manufatura), fazer com que esses sentimentos ganhem corporificações, tornem-se visíveis, finalmente acessíveis fenomenologicamente. $\mathrm{O}$ homem, em suas potencialidades comunicativas e diante da possibilidade da intersubjetividade, consegue fazer com que apareçam no mundo as intensidades que lhe eram anterior- 
mente exclusivas em sua introspecção, não acessíveis por outros: "Em cada caso, uma capacidade humana que, por sua própria natureza, é comunicativa e aberta-ao-mundo [world-open], transcende e libera no mundo uma apaixonada intensidade que estava aprisionada no si-mesmo [self]" (Ibidem, p. 210).

É através desse eixo - o da criação artística, o do ponto de vista do criador da obra de arte - que Arendt endereçará os aspectos essenciais da arte. $\mathrm{O}$ ponto, pelo menos assim nos parece, consiste em mostrar ao seu leitor que o processo de reificação tal como foi desenvolvido em seções anteriores de $A$ condição humana quando sua autora falava sobre o trabalho, ou mesmo sobre a produção de coisas utilitárias que compõem junto da arte a obra, não é totalmente adequado quando considera-se o surgimento da arte, ou melhor, a criação artística. Arendt parece sugerir que a obra de arte, quando considerada do ponto de vista da criação, exige de nós que pensemos a reificação como algo transfigurativo, que não só faz surgir no mundo através da manufatura uma coisa que não gozava de um estatuto ontológico objetivo, mas que faz com que essa coisa surja no mundo impulsionada pelo pensamento e catalisada pelos sentimentos humanos com vias a sua comunicação.

\begin{abstract}
No caso das obras de arte, a reificação é algo mais que mera transformação; é uma transfiguração, uma verdadeira metamorfose, como se o curso da natureza, que requer que tudo queime até virar cinzas, fosse invertido de modo que até o pó pudesse irromper em chamas. As obras de arte são coisas do pensamento, mas nem por isso deixam de ser coisas. O processo do pensamento não é capaz de produzir e fabricar por si próprio coisas tangíveis, como livros, pinturas, esculturas ou composições, da mesma forma como o uso é incapaz de produzir e fabricar por si próprio casas e móveis. Naturalmente, a reificação que ocorre quando se escreve algo, quando se pinta uma imagem ou se modela uma figura ou se compõe uma melodia, tem a ver com o pensamento que a precede; mas o que realmente transforma o pensamento em realidade e fabrica as coisas do pensamento é a mesma manufatura [workmanship] que, com a ajuda do instrumento primordial que são as mãos humanas, constrói as coisas duráveis do artificio humano (Ibidem, p. 211).
\end{abstract}

A arte, em Arendt, ganhará seu espaço de consideração filosófica ao ser inscrita dentro dos liames de uma investigação mais ampla sobre o processo de criação artística. Ademais, esse processo de criação, dentro de uma teorização, quiçá, expressionista, depende de uma série de parti pris que se relacionam com outras considerações de aspectos e processos que são semi- 
nais em seu empreendimento filosófico, isto é, a arte não ganha uma investigação autônoma, desenraizada de uma consideração atenta de outros fenômenos. Pelo contrário, se alia e se engasta a essas investigações. Tentamos, ainda que rapidamente, indicar, por exemplo, em que sentidos o conceito de mundo em Arendt dependia, de um lado, de uma herança (que ela mesma soube dimensionar) dos empreendimentos husserlianos e heideggerianos e, de outro lado, de sua consideração do conceito de obra enquanto aquela produção humana que sustém, estabiliza e faz com que apareça - para os homens mortais, submetidos aos seus limites orgânicos - a permanência e a solidez de sua produção. E, por fim, procuramos indicar que a noção de obra de arte em Arendt faz parte de um conceito cujo escopo é mais amplo, a saber, o conceito de obra.

Abordar, como fez Arendt, a arte a partir de seu processo de criação, aliando-a a outras instâncias de sua reflexão filosófica, parece à primeira vista como algo que, não só moderniza, mas também revisita toda uma tendência metafísica tradicional que insiste em explorar de certo modo a res extensa, objetivamente garantida. Revisitando-a parece, também, em especial com sua consideração da arte a partir do ângulo da criação e da expressão, evidenciar as maneiras pelas quais a res cogitans consegue corporificar-se e construir o mundo.

\section{O conceito de forma de vida (Lebensform) em Wittgenstein}

O conceito forma de vida (Lebensform) foi introduzido por Wittgenstein, na primeira parte de Investigações Filosóficas. O texto, que foi publicado postumamente na edição inglesa de E. M. Anscombe e Rush Rhees, consiste em um breve prefácio seguido de duas longas partes ou seções.

O prefácio de Investigações Filosóficas indica que as páginas que se seguem - e que contém as "precipitações (Niederschlag) de investigações filosóficas que me ocuparam ao longo dos últimos dezesseis anos" (Wittgenstein, 2009, p. 3e) - só poderão ser vistas sob um ângulo adequado se forem contrastadas com o pano de fundo do velho modo de pensar do Tractatus Logico-Philosophicus, o primeiro livro de Wittgenstein (Ibidem, p. 4e). Nele, podemos encontrar uma consideração forte sobre a natureza da lingua- 
gem, inteiramente dependente de uma "teoria da representação que requer um isomorfismo formal e estrito entre o sistema das proposições elementares e a totalidade dos fatos possíveis" (McGinn, 1997, p. 49), de modo que, na linguagem, portanto, "um nome está por uma coisa, e outro nome por outra coisa" (Wittgenstein, 2004, 4.0311, p. 26). O isomorfismo, formal e estrito, entre o sistema das proposições da linguagem e a totalidade dos fatos faz avançar, portanto, a ideia de que um nome é uma representação (um substituto discursivo) de uma coisa. A essência da linguagem, sua característica mais relevante, consistiria portanto em sua capacidade de nomear e de descrever factualmente a realidade. Sua função, neste sentido, é de constituir um nexo formal com o mundo que ela representa. Poder-se-ia dizer que essa teoria sobre a essência da linguagem faz referência, grosso modo, à natureza simbólica da linguagem. Ou seja, a linguagem emprega símbolos na forma de palavras ('cadeira', 'livro', etc.) que presentificam o objeto, ou que se encontram numa relação de substituição com ele. O empreendimento teorético do Tractatus Logico-Philosophicus consistirá, desse modo, no oferecimento de uma teoria da representação para a compreensão da natureza da linguagem.

A ideia central da teoria consiste na alegação de que proposições são um tipo de retrato. A proposição consiste de elementos (nomes) colocados numa relação determinada uns com os outros. A proposição representa um estado de coisas possível na medida em que os elementos da proposição (os nomes) estão por objetos e a relação entre os nomes dentro da proposição representa um possível arranjo de objetos pelos quais os nomes estão por (McGinn, 1997, p. 34-35).

Frente ao empreendimento teorético tractariano, encontramos em Investigações Filosóficas um empreendimento que dispensa o desenvolvimento de qualquer teoria e que incidirá criticamente sobre os fundamentos dessa primeira teoria da representação. Segundo a sugestão de McGuinn, Wittgenstein em Investigações Filosóficas não nos oferecerá nenhuma teoria, mas sim certas imagens da linguagem que servirão ao leitor enquanto objeto de comparação, desinvestindo nele uma tentação metafísica em enxergar a linguagem como algo completamente abstraído de seu uso em diferentes contextos (Ibidem, p. 49). Por essa razão, que o texto de Investigações Filosóficas se encontra costurado a uma miríade de exemplos e de situações 
imaginadas (Gedankenexperiment), uma vez que a consideração e a análise de contextos concretos que envolvem o uso da linguagem afasta uma tentação natural em pensar sobre ela sempre de modo abstraído de seu uso, procurando para ela uma certa essência da significação; nesse sentido, o ponto relevante será sempre considerar a linguagem em seu funcionamento uma vez que isso nos permite perceber que diferentes expressões desempenham também diferentes papeis, que o uso da linguagem encontra-se sempre vinculado à atividades não-linguisticas, e, por fim, que é no uso que as distinções mais sutis entre funções de expressões se tornam aparentes (Ibidem, p. 40). Por essas razões, de acordo com McGinn (1997, p. 43), é que a noção de jogo de linguagem será introduzida por Wittgenstein - como um modo de conferir proeminência ao fato de que a linguagem sempre funciona dentro daqueles contextos ativos e práticos nos quais os falantes vivem, contextos nos quais o uso da linguagem está sempre relacionado a uma diversidade de comportamentos (especialmente comportamentos não linguísticos).

O conceito wittgensteiniano de jogos de linguagem serve claramente como um modo de sobrepor e também de contraria a ideia da linguagem como um sistema de símbolos significativos que pode ser considerada em completa abstração de seu emprego efetivo. Em vez de abordar a linguagem enquanto um sistema de signos dotados de significado, somos incitados a pensa-la in situ, incorporada nas vidas daquelas que a falam. A tendência em isolar a linguagem, ou em abstraí-la daqueles contextos nos quais ela ordinariamente vive, encontra-se vinculada a adoção de uma atitude teorética em relação a ela e, também, a nossa urgência em explicar como esses meros signos (essas meras marcas) podem adquirir um poder extraordinário de significar ou representar alguma coisa. O objetivo de Wittgenstein é nos mostrar que através desse ato de abstração, nós damos as costas para tudo que é essencial para o funcionamento da linguagem; é o nosso ato de abstraí-la do seu emprego dentro das nossas vidas ordinárias que acaba por transformá-la em algo morto, cuja habilidade de representar agora clama por explicação (Ibidem, p. 45).

O abandono por parte de Wittgenstein da ideia de uma teoria e sua adoção de uma abordagem diferente, a partir da qual são apresentadas sucessivas imagens que exigem, conforme seu aparecimento, a comparação ao pano de fundo tractariano, permite que Wittgenstein abandone também o comprometimento com a suposição de uma estrutura essencial que circunscreva limites e que esquadrinhe as fronteiras entre o que é e o que não é uma linguagem. O que suscita, igualmente, uma consideração sobre a completude de uma linguagem. 
Não faz sentido falar da linguagem como algo completo ou incompleto. Pois a linguagem representa um tipo de limite àqueles que a falam; ela representa o ponto do qual nós julgamos. Nossa linguagem não é superior àquela dos jogos de linguagem que Wittgenstein descreve no sentido de estar mais próxima de um simbolismo ideal, ou completo; ela é simplesmente mais rica e mais complexa. O conceito de incompletude, assim como o de completude, pertencem à ideia falsa de um absolutamente correto ou essencial sistema de representação (Ibidem, p. 50).

Cavell em Declining Decline: Wittgenstein as a Philosopher of Culture (1988) procurará sugerir uma leitura na qual considera Investigações Filosóficas como uma filosofia da cultura. Para Cavell (1988, p. 254), esse tipo de leitura consegue nos colocar numa direção mais adequada para responder questões essenciais e que são suscitadas pela obra de Wittgenstein, a saber: (1) em que consiste o aspecto ordinário da linguagem? E (2) o que são as formas de vida (Lebensform)?

Em relação ao aspecto ordinário da linguagem, Cavell (1988, p. 254) encontrará em Wittgenstein um questionamento sobre o uso da linguagem se a palavra é alguma vez usada em um jogo de linguagem que é a sua casa (Heimat) original - como uma contraposição ao uso da linguagem em seu uso filosófico. Wittgenstein parece crer que no último caso, as palavras são em certo sentido retiradas do seu lugar ordinário, do lugar usual que ocupam, e são empregadas em sentidos e contextos bastante distintos. Essa consideração atesta com premência uma dimensão até então desconsiderada do ponto de vista filosófico: de que as palavras, no uso que fazemos delas para a reflexão filosófica, como que saem do seu lugar habitual, da sua casa (Heimat). Isso implica, parece-nos, que nesse processo de desapropriação do lugar habitual da palavra, ela acaba também abandonando todo o seu dimensionamento histórico e cultural, e que se encontra concentrado no seu uso ordinário.

Já em relação à pergunta pelo conceito de forma de vida - que é uma noção mais bem delineada em Investigações Filosóficas, mas que pode encontrar seus primeiros contornos em O Livro Azul - Cavell a tomará como uma espécie de expediente cuja função é "enfatizar a natureza social da linguagem e da conduta humanas" (Ibidem, p. 254). A dimensão social aludida por Cavell, refere-se a um sentido horizontal (ou antropológico) de uma forma de vida que não excluí, contudo, a possibilidade de um sentido vertical. 
O sentido horizontal diz respeito a certas convenções ou acordos entre os sujeitos e que se encontram instauradas no tecido de uma cultura - por exemplo, as diferenças entre o escambo e o sistema de crédito, ou entre o que significa uma posse e uma coroação dentro de sistemas políticos (Ibidem, p. 255). E o sentido vertical diz respeito aos graus de complexidade biológica e evolutiva - por exemplo, as diferenças entre pegar a comida com um garfo ou com um bico, ou entre seres vivos com polegares opositores e seres vivos sem eles (Ibidem). Ao retomar o trecho inicial de Investigações Filosóficas, Cavell procura assentar que o trecho de Agostinho mencionado por Wittgenstein opera como uma verdadeira inflexão, dando-se sobre o restante do texto, uma vez que é uma cena de herança.

\begin{abstract}
Investigações é uma obra que inicia com uma cena de herança, a herança da linguagem por uma criança; ela é uma imagem da cultura como herança, uma herança que acontece, como é fundamental para Freud, no conflito entre gerações (...). A penetração e a determinação da figura da criança em Investigações Filosóficas é estabelecida pelo fato de que Wittgenstein decide encabeçar o seu livro com o parágrafo de Santo Agostinho, que dita a cena de herança e instrução e de testemunho ou fascinação. As palavras de Santo Agostinho determinam precisamente os tópicos do livro de Wittgenstein como um todo, de modo que a cena das suas palavras permeia o livro (Ibidem, p. 259).
\end{abstract}

O que Cavell procura mostrar ao leitor é que essa herança que aparece ilustrada em Santo Agostinho (e que Wittgenstein recupera) é também a nossa herança à respeito do que compreendemos como uma linguagem. Nesse sentido, são as nossas exigências e a nossa determinação em nos mantermos ferrenhamente possuidores dela que configuram o próprio núcleo daquilo que incentiva e fomenta dentro de nós uma tentativa de teorização sobre a linguagem. Nesse sentido, pensar no exemplo mais emblemático para aprendizagem da linguagem é algo elucidativo, já que ele se dá na dimensão de um ensino ostensivo - a criança aprende o emprego o emprego das palavras 'mãe' e 'pai' por uma espécie de treinamento, onde o ato de apontar para aquela pessoa que é sua mãe é naturalmente sobreposto ao proferimento da palavra 'mãe'. Disso, parece se desdobrar com bastante clareza a dimensão histórica, transgeracional, salientada por Cavell em relação ao modo de compreender a linguagem. Ela não se configura como um conjunto procedimental dado desde que nascemos. Ao contrário, é algo que nos é transmitido e que, da mesma forma que nos é transmitido, também foi por 
sua vez transmitido àqueles que nos transmitiram. Isso atesta, em larga medida, um processo de transmissão histórica da linguagem e, dentro dela, de termos, definições, expressões e, ainda sobrepondo-se a isso, de transmissão do uso apropriado desses elementos nos seus contextos mais diversos.

Desse modo, é legítimo compreender que o conceito de forma de vida é empregado no horizonte de Investigações Filosóficas como um forma de destacar a ideia de que a linguagem, seu aprendizado e sua transmissão, estão sempre relacionados ao uso e que esse uso, por sua vez, dá-se sempre numa dimensão prática da vida humana e da ordinariedade de seus comportamentos.

A ideia de uma linguagem como uma forma de vida, como a ideia de um jogo de linguagem, é para ser sobreposta à ideia de linguagem enquanto um sistema abstrato de signos; ela serve novamente para dar proeminência ao fato de que a linguagem está incorporada no horizonte do comportamento significativo e não linguístico. Assim, exatamente como o termo 'jogo de linguagem' serve para evocar a ideia da linguagem em uso entre as atividades não linguísticas dos falantes, o termo 'forma de vida' serve para evocar a ideia de que a linguagem e a troca linguística se encontram incorporados na significativamente estruturada vida grupal de agentes humanos ativos (McGinn, 1997, p. 50 a 51).

A noção de forma de vida é, no entanto, mais sugestiva que a de 'jogo de linguagem' no sentido de que confere a essa discussão sobre a linguagem um novo grau de complexidade. Ela sugere, em especial, que a linguagem não pode ser pensada em seu emprego nos casos particulares ou concretos; mas que esses casos possuem diferenças, algumas mais agudas, outras mais sutis; que eles podem ser pensados em termos históricos, temporais e geográficos; que eles atravessam transformações ou repetições. Nesse sentido, o sentido de 'vida' que circunscreve parte da noção amplia-se.

O conceito de vida, conforme Wittgenstein o emprega aqui, não é o de vida biológica, nem o de uma ideia a-histórica da vida de uma espécie em particular. A ideia de forma de vida se aplica, antes, aos grupos históricos de indivíduos que estão conectados juntos em uma comunidade através de um conjunto de práticas complexas e que se desenvolvem linguisticamente. Essas práticas estão assentadas em demandas biológicas e capacidades, mas enquanto estas últimas são mediadas e transformadas por um conjunto de jogos de linguagem intricados e historicamente específicos, a nossa forma de vida humana é fundamentalmente cultural (em vez de biológica) em sua natureza. Vir a compartilhar, ou compreender, a forma de vida de um grupo de seres humanos individuais significa dominar, ou vir a compreender, os intricados jogos de linguagem que são essenciais para as suas 
práticas características. É esta conexão vital entre linguagem e o complexo sistema de práticas e atividades que unem uma comunidade é o que Wittgenstein procura enfatizar no conceito de 'forma de vida' (Ibidem, $p$. $51)$.

\section{Considerações Finais}

Tanto em Hannah Arendt, como em Wittgenstein, podemos encontrar esboçada e filosoficamente trabalhada a ideia de que o mundo é algo humana construído. E isso, porque, ao redimensionarem um conceito ontológico tradicional, procuram mostrar que é preciso reconhecer uma instância da existência das coisas que parece naturalizar-se, mas que cuja origem e cuja construção remetem inexoravelmente ao artifício humano.

Em Arendt, o mundo aparece como o lugar privilegiado para compreendermos a obra e, dentro dela, a obra de arte. O mundo constitui-se como um espaço no qual os homens podem estar entre homens (inter homines esse) e ingressarem nas vivências políticas, em especial a da pluralidade. Esse mundo, longe de ser garantido ta physei ou to taumathou, é garantido pela manufatura humana, seara do homo faber, e pela sua capacidade - na arte - de corporificar e transfigurar pensamentos e sentimentos em coisas reais.

Em Wittgenstein, através de seu reposicionamento filosófico em relação à linguagem, encontramos também a necessidade de levar em conta uma série de aspectos não-linguísticos e também não-simbólicos que ingressam no território do que deve ser considerado como linguagem, como o fenômeno da comunicação humana. Sua avaliação das formas de vida, pretende endereçar o problema da velha - e eficaz - imagem agostiniana sobre o funcionamento e natureza da linguagem, mostrando que ela é insuficiente para dar conta teórica e filosoficamente do todo que corresponde à linguagem humana. Falar de formas de vida, em Wittgenstein, significa falar principalmente da consideração necessária (no sentido lógico da necessidade) de aspectos culturais, práticos e extra-linguisticos que ingressam com premência e relevância dentro do âmbito funcional da comunicação e da intersubjetividade. $\mathrm{O}$ ponto aqui parece corresponder à necessidade, agora exegética, de compreendermos esse horizonte ampliado do conceito de for- 
ma de vida, como pretenderam nos mostrar Cavell e McGuinn, e reconhecer que nele também se encontra envolvida aquele caráter de pluralidade assentado por Hannah Arendt como um dos traços fundamentais do mundo.

\section{Referências}

ARENDT, Hannah. A condição humana. Rio de Janeiro: Editora Forense, 2013.

ARISTÓTELES. Metafísica. (Tradução e Comentários de David Bostock). Oxford: Clarendon Press, 2003.

CAVELL, Stanley. Declining decline: Wittgenstein as a philosopher of culture. In Inquiry: An Interdisciplinary Jounal of Philosophy, volume 31, número 3, p. 253-264, 1988.

DANTO, Arthur. The Artworld. In The Journal of Philosophy, volume 61, número 19, p. 571-584, 1964.

DUARTE, André. O Pensamento à Sombra da Ruptura: Política e Filosofia em Hannah Arendt. São Paulo: Paz e Terra, 2000.

GEACH, Peter. Logic Matters. Oxford: Basil-Blackwell, 1972.

MACGINN, Marie. Wittgenstein and the Philosophical Investigations. Londres: Taylor \& Francis, 1997.

PASSOS, Fábio dos. O Conceito De Mundo em Hannah Arendt: Um passo em direção à superação do hiato entre Filosofia e Política, 2013, p. 78.

WITTGENSTEIN, Ludwig. Philosophische Untersuchungen Philosophical Investigations. ANSCOMBE, G., HACKER, P. \& SCHULTE, J. (Trad.). Oxford: Basil-Blackwell, 2009. 